\title{
COMUNICACIÓN REAL Y APARENTE EN LA ENTREVISTA CLÍNICA: Modelo del doble espejo
}

\author{
Jaime de las HERAS SALORD \\ Universidad de Castilla-La Mancha \\ Jaime.Heras@uclm.es
}

\begin{abstract}
REAL AND APPARENT COMMUNICATION IN THE CLINICAL ENCOUNTER: The "double mirror" model
\end{abstract}

Resumen: La implementación de los Programas de Salud basados en la declaración de Alma Ata implica la subordinación a referentes políticos e institucionales y la priorización de metodologías cuantitativas. La comunidad es capaz de defenderse de la intrusión de la medicina científica y conjura la violencia estructural eludiendo una entrega incondicional como colectivo alógeno a la Medicina Hegemónica. Se genera así una falacia comunicativa en la que se producen diversas transacciones. A través de ellas pugnan intersubjetividad y dominación, amparada ésta última en una noción de progreso tecnológico contrapuesta en bastante medida a la necesidad de una voz empática. Según el Modelo del doble espejo en el encuentro clínico, gran parte de la información retorna hacia el actor correspondiente como un eco: en el caso del médico, la pretendida docencia de su propia cosmogonía y, en el caso del paciente, el embodiment de su experiencia cotidiana.

Abstract: The implementation of the Declaration of Alma Ata-based health programs implies the subordination to political and institutional concerns and the prioritization of quantitative methodologies over qualitative. The community is able to protect itself from the intrusion of Scientific Medicine and conjures the structural violence by avoiding an unconditional surrender as an allogenic collective in relation to Hegemonic Medicine. Several communicative fallacies, in which different transactions occur, are thus generated. Through them are fighting intersubjectivity and domination, sheltered this latter from the notion of technological progress, opposed to some extent to the need of an empathetic voice. According to the model of the double mirror in the clinical encounter, much of the information returns to the corresponding actor like an echo: in the case of the doctors, the ostensible teaching of their own cosmogony and, in the case of the patients, the embodiment of their daily experience.

Palabras clave: Comunicación. Medicina hegemónica. Dominación. Doble espejo Communication. Hegemonic medicine. Domination. Double mirror 


\section{Introducción}

En el encuentro clínico los sistemas de creencias del pueblo médico, entendido como el "conjunto de personas ajenas a los profesionales de la salud" (Fresquet y Aguirre, 2006: 136), se enfrentan a los paradigmas científicos en un verdadero tour de force en el que compiten distintas nociones e interpretaciones acerca de la enfermedad, acontecimiento en el que confluyen biología, cultura y sociedad, configurando, en términos de Mauss, un hecho social total (Martínez Hernáez, 2008: 172-173).

En este escenario, la biomedicina, en su tendencia expansiva hacia la hegemonía (Menéndez, 1992), trata de colonizar los espacios físicos y psicológicos del individuo-paciente para impregnarlos de su lógica, lo que conduce en definitiva a una modulación de sus actos, su sexualidad o sus hábitos. A esta tentativa de construcción de un nuevo sentido común contribuyen en gran medida las aportaciones de los media, como televisión e internet, reforzando tanto la imagen de un ser vulnerable que debe estar permanentemente vigilante a las señales de su cuerpo como el protagonismo de la responsabilidad individual del hecho de enfermar, soslayando a menudo la realidad social, económica y política ${ }^{1}$. Las actividades preventivas, diseñadas en general para colectivos poblacionales estratificados por edades, tienden a cubrir todas las etapas vitales de los individuos e incrementan eficazmente dicha vigilancia. En gran medida, la finalidad de estas alertas permanentes radica en estrategias biopolíticas de sumisión y control social ${ }^{2}$. En el caso de las mujeres dicho control parece ser más estricto y es auxiliado por la medicalización de procesos fisiológicos, como la reproducción y la menopausia. Cada uno de los programas de salud implica diversas visitas al profesional sanitario, en las cuales se refuerza la lógica biomédica a menudo con el apoyo de pruebas diagnósticas, como los análisis de sangre, y de prescripción de medicamentos profilácticos que, a menudo, son vistos como innecesarios, incluso desde buena parte del colectivo médico ${ }^{3}$.

El análisis que se presenta en este trabajo parte de una etnografía realizada entre 2007 y 2010 en una Zona Básica de Salud de la comarca de La Manchuela, ubicada en el norte de la provincia de Albacete en la Comunidad Autónoma de Castilla La Mancha (España). Dicha unidad asistencial atendía a ocho mil personas distribuidas en diez núcleos poblacionales a través de un equipo compuesto por ocho médicos y siete enfermeros que se reunían periódicamente en el Centro de Salud de la cabecera, localizada en Casas de Juan Núñez. Se llevó a cabo observación participante en dichas reuniones durante un año y se realizaron cincuenta entrevistas semiestructuradas orientadas a la percepción de la salud, los modelos explicativos de las enfermedades, los hábitos saludables y, sobre todo, a la relación con los profesionales en el encuentro clínico.

\section{Resultados}

\section{Programas y discursos}

Una parte mayoritaria de nuestros informantes centran la causa y el devenir de la enfermedad en dos cuestiones elementales, relacionadas con los designios divinos y con la

\footnotetext{
1 La antropóloga estadounidense Nancy Scheper-Hughes realizó un análisis ya clásico de la instrumentalización de la biomedicina en este sentido, medicalizando la pobreza para transformar un problema político de inequidad social en una supuesta enfermedad abordable con fármacos. Véase al respecto "Nervoso" (Scheper-Hugues, 1997: 167-212).

2 Foucault, 1996: 87. Una revisión sobre este tema puede leerse en Rodríguez Zoya, 2010: 1-27.

3 Entre la abundante bibliografía acerca de esta cuestión baste citar los estudios sobre el uso de anticoagulantes (Hsu et al., 2015), y de vacunas contra la gripe A (Gervás y Hernández, 2011) o el Virus del Papiloma Humano (Tomljenovic, Spinosa y Shaw, 2013).
} 
naturaleza de las personas. La numinosidad parece estar siempre presente en el proceso de enfermar y sanar, aunque en el mismo intervengan profesionales o terapeutas tradicionales. En cuanto a la naturaleza se trata de un concepto que refiere a determinadas características familiares heredables. La actuación humana queda, por tanto, en un segundo plano en todo momento. La misma lógica que inspira estas nociones es la que parece determinar la fortuna individual y colectiva, tras de la cual basculan los sistemas productivos. Esta percepción en cierto modo determinista de la salud dificulta enormemente la adherencia de la población a los Programas de Salud. De hecho, una cuarta parte de la misma no visita los espacios biosanitarios durante años, temerosa de ser censurada por sus pautas habituales de conducta y, en definitiva, de ser redirigida hacia otras formas de comportamiento más acordes con la ortodoxia médico-científica.

Estos programas comenzaron a aplicarse localmente de una manera operativa hacia comienzos del milenio, aunque derivaban de la importante reforma sanitaria que tuvo lugar en España a partir de la Ley General de Sanidad de 1986. Habían nacido de los presupuestos teóricos de Alma Ata, que consideraban la salud desde una perspectiva holística, pero su aplicación en la mayor parte de países fue sesgada debido a la subordinación a referentes políticos e institucionales (Almeida, 2009: 341-342) y a la priorización de metodologías cuantitativas frente a las cualitativas (Minayo y Sanches, 1993: 239-262; Almeida, 2007: 229-233). En nuestro país dichos protocolos vertebraron los aspectos preventivos de la Atención Primaria, que habían sido extraordinariamente rudimentarios hasta la última década del siglo XX.

La puesta en práctica de estos programas y sus respectivos subprogramas encuentra a menudo una fuerte resistencia en la población debido a la presión que ejercen sobre sus creencias y sus hábitos tradicionales. Uno de los ejemplos más significativos en este sentido es el protocolo de abordaje contra la obesidad, considerada por muchos informantes como un signo de salud y/o de opulencia, en contraposición a la delgadez, que evoca la pobreza y la escasez de alimentos y que acompaña a enfermedades graves como el cáncer. Los programas orientados al tratamiento de esta enfermedad biomédica fracasan sistemáticamente en nuestro objeto de estudio. Los sanitarios tratan de aplicarlos utilizando refuerzos negativos y positivos durante años sin conseguir resultados. Esta situación es comparable a otras alteraciones de la salud -siempre desde el punto de vista científico- en las que los factores culturales tienen un peso importante. Estas cuestiones ya habían sido puestas de manifiesto por diversos autores con el fin de exigir una epidemiología que trascendiera los modelos interpretativos hegemónicos para visibilizar de un modo holístico la realidad socio-sanitaria (González Chévez y Hersch-Martínez, 1993: 401; Barreto, Almeida y Breilh, 2001: 158-159), demandando una epidemiología sintética (Menéndez, 2008: 41). Esta perspectiva se caracterizaría por considerar como variables epidemiológicas en los procesos de salud/enfermedad/atención no solo los aspectos biológicos sino también los culturales y los económico-políticos, y por aplicar un enfoque relacional referido a los actores sociales que intervienen en dichos procesos (Menéndez 2009: 131-132).

Una primera mirada acerca del poder coercitivo de tales iniciativas sugiere la existencia de un proceso aculturador entre la población que recibe la influencia de esta forma intrusiva de Medicina. Sin embargo, como se ilustra con el ejemplo de la obesidad, la sumisión que se representa en el encuentro clínico no parece implicar una renuncia del pueblo médico a sus concepciones teóricas en materia de salud. En este sentido la Medicina científica complementaría a otros recursos terapéuticos, entre los que la autoatención ocupa habitualmente el lugar preeminente puesto que, como señala Menéndez,

"la autoatención constituye no sólo la forma de atención más constante sino el principal núcleo de articulación práctica de las diferentes formas de atención, 
la mayoría de las cuales no puede funcionar completamente sino se articula con el proceso de autoatención" (Menéndez 2003: 191).

Así, la performatividad del discurso médico-científico no parece influir sensiblemente en los elementos estructurales comunitarios en el sentido de modificar sus perspectivas sociales, ideológicas o políticas sino que, alternativamente, se orienta hacia la construcción de un capital simbólico basado en la enfermedad. Apoya esta tesis la constatación de que muchos individuos ven en el discurso médico una vía alternativa para recuperar simbólicamente su estatus perdido, fenómeno que podemos incardinar en la noción de beneficio del enfermo esgrimida por Parsons (1984: 406-407). Dicho capital contrarrestaría las carencias de un sistema injusto de distribución social de roles y relaciones de poder. Este reequilibrio aflora con notable singularidad entre las mujeres mayores de cincuenta años que experimentan el síndrome denominado "del nido vacío" así como entre un gran contingente de personas ancianas, que perdieron su antiguo poder y representatividad social a expensas de la transformación industrial sufrida en el medio rural español en los años cincuenta del siglo XX (De las Heras 2014a: 149-154). En el primer caso hemos constatado a menudo cómo el taxón diagnóstico de depresión tiende a invisibilizar el conflicto social que subyace en la etiología ${ }^{4}$, mientras que en el segundo las consecuencias de la herida individual asociada a la pérdida de rol parecen compensarse mediante la acumulación de un capital simbólico basado en la enfermedad. En ambos casos se justifica una disfuncionalidad a expensas de una dolencia pero, subrepticiamente, se neutraliza la violencia estructural mediante un proceso de medicalización. En ocasiones hemos advertido incluso cierto encarnizamiento diagnóstico y terapéutico en este sentido, sobre todo cuando desde la perspectiva biomédica se catalogan como enfermedades los signos y síntomas que acompañan habitualmente al envejecimiento.

\section{Un modelo relacional: el doble espejo}

La mayoría de los pacientes analizados en nuestro estudio alberga mitos y creencias en torno a la salud vinculadas a los paradigmas comunitarios, transmitidos principalmente por sus madres y abuelas. En su acervo terapéutico privilegian las estrategias de autoatención y de medicina popular, sobre todo en el contexto de la numinosidad y de las redes familiares y sociales. Con menor frecuencia asisten a las consultas de los médicos científicos, motivados en estos casos por su prestigio profesional y por los beneficios secundarios ligados al rol de enfermo. En dicho espacio mantienen sus propias construcciones y presupuestos teóricos, tratando de armonizarlos en alguna medida con el discurso biomédico que, igual que acontece con las pruebas diagnósticas y los elementos terapéuticos, reinterpretan en clave local.

A pesar de esta disociación teórica, muchos pacientes creen alcanzar un óptimo nivel de comunicación por cuanto su illness es aceptada y oficializada como disease e incluso, en ciertas ocasiones, obtienen un beneficio esperado de la mano del sanador científico. Los médicos, por su parte, creen haber obtenido una confianza basada en una cierta conversión de los pacientes a los esquemas teóricos de su práctica, por cuanto éstos parecen asumir sus diagnósticos y tratamientos. No obstante, esa transferencia de significados es sólo aparente. Entre ambos actores parece operar un filtro que podemos comparar a un doble espejo.

4 Entendemos que existe un conflicto social debido a la existencia de una priorización generalizada de la función reproductiva en la mujer desde la socialización primaria. Por dicha razón, cuando el último de los hijos abandona definitivamente el hogar familiar, la madre se ve obligada a afrontar frecuentemente un vacío existencial, difícil de llenar tras varias décadas de dedicación, a menudo exclusiva, al cuidado de la prole. Muchos Estados, de cuyos presupuestos doctrinales explícitos o implícitos deriva esta asignación de rol a las mujeres, no prevén soluciones a este problema, probablemente porque se trata de personas que no desarrollan una actividad productiva útil al sistema político-económico. 
A través de este filtro -y en proporción directa al afán de los actores por comprender la subjetividad del otro (Gómez Esteban, 2002: 65-84)- fluirían las intenciones y deseos, la necesidad de asumir por ambas partes que existe un padecimiento y la voluntad de aplicar los recursos para aliviarlo. Pero la categorización de la dolencia, su modelo explicativo e, incluso, el abordaje terapéutico, hallarían un freno en dicho filtro. En los dos primeros casos la reflexión sería prácticamente total, mientras que en lo que respecta al tratamiento ciertos elementos se reflejarían hacia quien los emite y otros serían capaces de atravesar el filtro, como se esquematiza en la ilustración 1.

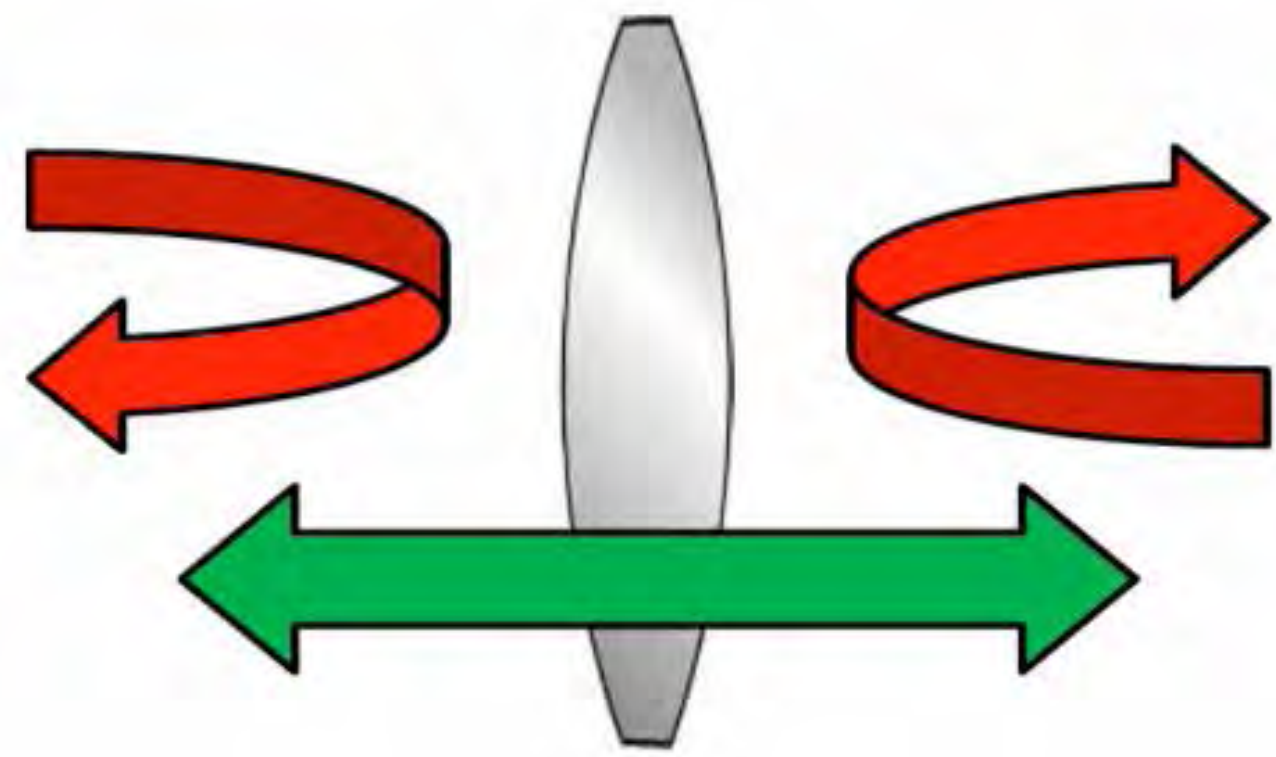

Ilustración 1. Modelo del doble espejo. Parte de la información fluye libremente entre ambos interlocutores mientras que otros contenidos son reflejados hacia su emisor por un filtro virtual interpuesto. Ambos agentes creen recibir y transmitirse información pero parte de la misma procede de sí mismos formando un bucle en el espejo. Elaboración propia.

Una ventana epistemológica que permite aproximarse a este fenómeno radica en la constatación de un doble flujo de mentiras en la entrevista clínica como propone Fainzang (2002: 117-133), para quien médicos y pacientes mienten inconscientemente compelidos por la relación de poder que existe entre ellos y en la que la sumisión del paciente encubre el ejercicio de su poder de elección. Pero, más allá de la performance de roles sociales, gran parte de todo aquello que trasciende la cuestión de la integridad corporal en ambos discursos es reflejado hacia el actor emisor como un eco: en el caso del médico, la pretendida docencia de su propia cosmogonía y, en el caso del paciente, la encarnación -embodiment- de su experiencia cotidiana y los significados que ésta traduce de la realidad social y relacional, contenidos en su narrativa (Monks, 2000: 32).

El modelo del doble espejo se comporta en cierta medida como una aplicación específica del modelo de la habitación china propuesto por John Searle (1980: 417-457), en el cual un individuo aislado se comunica mediante un lenguaje cuyo significado ignora. Searle concibió este modelo como un alegato al test de Turing (Turing, 1950: 433-460) y su aplicación a los programas de Schank -entre otros-, que proponían de forma experimental la imposibilidad de discernir el origen de las respuestas a las preguntas que planteaba un investigador 
cuando se realizaban a una persona y a un ordenador. La habitación china es un espacio desconectado del exterior en que se aloja un individuo al que se han proporcionado diversas claves lógicas sobre la escritura china, lengua que desconoce por completo. Mediante esas claves, no obstante, es capaz de contestar a diversas preguntas que un colaborador le entrega a través de una ranura. Si el experimento está bien construido, la persona que proporciona las preguntas estará convencida de que el individuo que está dentro de la habitación conoce perfectamente la lengua china. Esta contradicción obedece al hecho, según Searle, de que ha sido adiestrado en la sintaxis china pero ignora por completo su semántica, faltando por tanto la intencionalidad en el proceso de comunicación.

\section{Algunas precisiones sobre los modelos relacionales y el doble espejo}

Los profesionales sanitarios de nuestra área de estudio comparten la convicción de que un segmento notable de sus pacientes no van a seguir sus recomendaciones, tanto por cuestiones identitarias ${ }^{5}$ como por una mala comprensión de los mensajes recibidos ${ }^{6}$. Según este discurso, existen muchos pacientes que no toman conciencia de la naturaleza y alcance de su proceso ni del riesgo que entraña debido a una falta de entendimiento con los profesionales y, por este motivo, éstos últimos deben insistir profusamente en las actividades de educación para la salud. Por otra parte, muchos pacientes reconocen no seguir al pie de la letra los consejos médicos y lo justifican con razonamientos como los siguientes:

1. Para muchos pacientes, los profesionales exageran acerca del riesgo para la salud que suponen ciertas enfermedades porque pretenden un estado -óptimo desde el punto de vista profesional-, que no es asumido como saludable por el usuario. Así acontece con el peso ideal propuesto por los profesionales, que es valorado a menudo por la comunidad como un estado de vulnerabilidad, contrario a la noción colectiva de reserva precautoria frente a situaciones de precariedad, como enfermedades prolongadas, inmovilizaciones en la cama o, sencillamente, falta de recursos económicos. Esta noción de previsión es universal, no sólo concierne a los elementos materiales -dinero, alimentos, ropa, etc.- sino también a los inmateriales como el capital moral, que provee respetabilidad por parte de la comunidad y de las entidades espirituales ${ }^{7}$. Análogamente al estado nutricional se tiende a relativizar la proscripción médica de determinadas desviaciones, en el sentido parsoniano de la palabra, como el consumo de alcohol o tabaco. De este modo se entiende que un razonable consumo de alcohol, por ejemplo, no pone en riesgo la salud. En la cantidad asociada a la noción de "razonable" intervienen factores como la edad, el sexo, el tipo de trabajo, el tipo de alimentación y el estado de salud pues, paradójicamente, se asumen que las personas enfermas no deben tomar bebidas alcohólicas porque, coyunturalmente, dificultan la curación al entorpecer la acción de las medidas terapéuticas. Estas conductas reflejan valores culturales y permiten incluso, más allá de los límites de la salud, la comisión de ciertos actos que transgreden las leyes, tanto civiles como consuetudinarias. No pueden obviarse en este

\footnotetext{
5 La expresión utilizada para verbalizar este fenómeno es "hacen lo que les da la gana", expresión que hace referencia a presupuestos culturales por parte de los pacientes que difieren de la lógica médica. Reunión de equipo del Centro de Salud 13-6-2007

$6 \mathrm{El}$ fracaso en la eficacia del proceso clínico-terapéutico se suele relacionar, desde la perspectiva biologicista de la Medicina Basada en la Evidencia, con la falta de comunicación clínica activa en la entrevista debida a la escasez de información suministrada al paciente por parte del médico (Moore, 2006: 385-386).

7 La economía doméstica tradicional de nuestra área de estudio incluía la provisión de alimentos para todo el siguiente año al iniciarse la estación invernal. Por otra parte la acumulación de capital moral, necesidad probablemente dimanada de la doctrina católica, facilita las transacciones con los numina. Dichas transacciones, como hemos señalado (De las Heras, 2015), poseen un carácter cuasi-mercantil y se implementan principalmente para obtener una mejoría del estado de salud. Mientras la costumbre de almacenar alimentos comenzó a decaer en los años sesenta del siglo XX, la de incrementar el prestigio moral para contender con los actores del espacio sagrado goza de plena vigencia en nuestros días.
} 
sentido determinadas situaciones de liminalidad, como ocurre con los ritos de paso de los quintos, en los que se consiente a los adolescentes emborracharse públicamente y robar en corrales y huertos.

2. Según el criterio de muchos pacientes, cuando los médicos manifiestan desear "lo mejor para la salud del paciente" parecen ignorar que muchas recomendaciones son difíciles o incluso, a veces imposibles de cumplir, aunque no dudan de sus beneficios. La figura del profesional se equipara en cierta medida a la del sacerdote, que comparte un discurso doctrinal ejemplar con un cuerpo pecador. En ambos casos se enfatiza un camino de perfección que, tácitamente, se reconoce como estrictamente ilustrativo.

3. Muchos pacientes señalan que, aunque el médico "pone de su parte", ejerciendo de esta forma el rol que la comunidad le asigna, la mayor parte de causas que influyen en la enfermedad son ajenas a ambos actores. En un sentido amplio se entiende que el orden social, del que el médico es un elemento estructural y un agente activo, puede sucumbir ante lo extraordinario, que se vincula habitualmente a un designio divino. La enfermedad individual constituiría así un peaje para conjurar el riesgo del cambio social

Los elementos que gravitan en la relación médico-paciente parecen proceder, en primer término, de concepciones paradigmáticas, aunque también intervienen cuestiones estrictamente relacionales. Si en la entrevista psiquiátrica éstas últimas cobran especial protagonismo por cuanto determinan la viabilidad de la terapia que, en definitiva, pretende visibilizar el paradigma del paciente ante la mirada del psiquiatra, en la entrevista clínica pasan a un segundo término. El médico no pretende por lo general acceder al sistema de creencias del paciente para modular su intervención aunque, indudablemente, la confianza y crédito en el sanador, verbalizados a menudo como "fe en el médico", influyen poderosamente en el resultado de la consulta. El modelo del doble espejo contempla esencialmente variables estructurales, aunque otras de tipo conductual pueden intervenir en el proceso de comunicación. A dicho proceso, por adoptar un aspecto externo de entendimiento aparente y poseer una realidad interna de disociación que permite, no obstante, culminarlo, puesto que ambos actores creen compartir más nociones de las que en realidad comparten, le hemos denominado "falacia comunicativa".

\section{La falacia comunicativa y los sistemas de transacciones}

A efectos prácticos podemos analizar esta variable a través de cuatro sistemas de transacciones que intervienen en la relación médico-paciente en un proceso-tipo como es el de los problemas respiratorios agudos, que se identifican con etiquetas disease/illness inicialmente compartidas. Queremos significar con esto que pertenecen al imaginario de ambos actores, situación que no se daría en el caso de dolencias dependientes de concepciones culturales (culture bound syndromes $^{8}$ ), aunque respondan a distintas etiologías y posean diferentes modelos explicativos para ambos actores.

\section{a. Transacciones de etiquetaje}

Los problemas respiratorios agudos se suelen relacionar en una escala de gravedad a lo largo del eje "resfriados-bronquitis- neumonías". Para los profesionales se trata de variables cualitativas o, en todo caso, cuantitativas discretas, mientras que para el pueblo médico son interpretadas como cuantitativas continuas. En esta función continua parecen intervenir variables dependientes en nuestro objeto de estudio, como:

1. El grado de penetración del mal: según el testimonio de muchos informantes,

8 Ejemplos de este tipo de patologías en nuestra área de estudio son el mal de ojo, el asiento, el malote y el estérico. 
en numerosas ocasiones la dolencia actúa como un animal que "se agarra" al interior del cuerpo. El pronóstico depende así de la intensidad con que acontece este fenómeno pudiendo, incluso, ocasionar la muerte.

2. El estado previo del enfermo al que, con carácter casi universal, una "flojedad" predispone a la enfermedad. La principal causa de flojedad obedece a un bajo peso, noción que incluye los márgenes de lo que en biomedicina se denomina peso normal o peso ideal.

3. La magnitud del virus, que no se suele interpretar como elemento infectivo independiente -al modo en que lo hacen médicos y biólogos- sino como miasma epidémica, ilustrada en los siguientes verbatims: "ese virus que anda por ahı̂", "en mi casa todos han cogido el virus ese menos...", "dicen que este año viene un agripe muy malo", etc.

4. A los síntomas, privilegiando la tos y el producto de la expectoración. La mayoría de los informantes advierten en la tos tres grados principales: la tos de "garrañera" o "ripio", que tiene un carácter leve y traduce una irritación de la garganta, la tos "de perro", que es insistente y revela una patología de mayor magnitud 9 y, finalmente, una tos que produce esputos. Esta es una "tos de viejo" y se considera de buen pronóstico porque "arranca" el mal, cuya intensidad se considera mayor o menor según el color del esputo. En base a esta taxonomía, la mayor parte de enfermos con tos seca solicitan al médico medicamentos que "les haga arrancar". Por el contrario, los profesionales consideran que la expectoración es una complicación de un proceso más leve y se niegan a hacer las radiografías que los pacientes solicitan cuando una tos improductiva se prolonga en el tiempo.

Por tanto, cuando a lo largo de la entrevista clínica se negocia el diagnóstico, la etiqueta final no refleja forzosamente la misma representación aunque sea compartida y satisfaga a ambas partes. Cada uno de los actores tiende a creer que el otro posee la misma noción del proceso que él y sin embargo, a medida que avanza el encuentro, la imagen del mismo será progresivamente distinta y el aparente entendimiento se sustentará en el simple hecho de que existen en ambos actores nichos epistemológicos en cierto modo equivalentes.

Con carácter excepcional se puede identificar un contexto en el que algunos médicos se apoderan de ciertos aspectos del discurso no profesional con una finalidad asimilacionista ${ }^{10}$. En la entrevista clínica ordinaria se negocian algunos aspectos de la aflicción, como la etiqueta o el tratamiento, aunque la mayoría de elementos transaccionales permanecen ignorados, la mayoría de ellos al sufrir una reflexión hacia su emisor en el espejo. Sin embargo, dicha negociación parece llevarse a cabo sin que ninguno de los dos actores renuncie a su paradigma. En el caso de la Medicina científica privada se observa a veces, en el contexto de una complacencia clientelista, cómo el profesional trata de utilizar el lenguaje del enfermo para que esa adecuación transferencial le resulte a éste más confortable y así poder fidelizar su confianza. En estos casos se utilizan etiquetas que, con aspecto científico, penetran en la cosmovisión del usuario para "venderle" 11 un diagnóstico como, por ejemplo, "principio

9 Este tipo de tos es sin duda el que causa el mayor motivo de preocupación. Adquiere especial gravedad en los lactantes que, tras una quinta de tos, a veces "se pasan", es decir que pierden el tono muscular y se quedan inconscientes. Esta situación genera una gran alarma pues es una creencia ampliamente compartida la posibilidad de que el infante llegue a morir o quede en un estado de debilidad mental por dicha razón.

10 La apropiación del discurso del otro es una constante histórica como elemento de dominación, en ocasiones favorecida por los propios antropólogos. Así, es un hecho conocido que la identificación de los paradigmas culturales de grupos humanos fue en el siglo XIX un enérgico desencadenante de los estudios antropológicos para allanar el camino al colonialismo.

11 En la tercera de las cinco fases descritas por Suchman para modelizar la experiencia de la enfermedad, se 
de neumonía", "principio de bronquitis", etc, que carecen de significado en la ortodoxia nosológica médico-científica.

\section{b. Transacciones etiológicas}

A pesar del cambio de rumbo tomado por la Medicina científica desde la segunda mitad del siglo XIX a partir del desarrollo de disciplinas como la química y la bacteriología, no es infrecuente hallar en su discurso algunos elementos de paradigmas anteriores. Así, el frío y la constitución corporal aparecen con cierta frecuencia en la base de las concepciones causales de los problemas respiratorios agudos, tanto para médicos como para profanos. La noción de constitución tiene, sin embargo, un significado distinto en ambos actores. Para los médicos de nuestra área de estudio el estado constitucional es producto y reflejo de una buena salud y una correcta alimentación, aunque reconocen la influencia de factores genéticos. Nuestros informantes propugnan una perspectiva más determinista, según la cual la constitución de la persona obedece principalmente a la herencia recibida de sus ancestros, verbalizada mediante la expresión "ser achacanto a...". Existirían así familias "achacantas" al cáncer, a la apendicitis o a los problemas respiratorios porque poseen una flojedad congénita y heredable que las predispone a padecer dichas dolencias. Por otra parte constituye una creencia generalizada la intervención en la causa de las enfermedades de la voluntad divina, que en ocasiones impone por este medio un castigo a la persona que cometió un desacato moral. Otras veces la enfermedad se impone por esta vía numinosa como una penitencia que, paradójicamente, señala al sujeto piadoso y le confiere la facultad de curar (De las Heras 2014b: 209-228)

En este tipo de transacciones, la falacia comunicativa se oculta bajo la adopción de términos-clave como frío, expectoración, virus, naturaleza de la persona y, a veces, incluso palabras técnicas por parte del médico como "síncope de la tos". Ambos actores creen entenderse a través de las mismas expresiones lingüísticas aunque sus representaciones sean distintas y, cuando se dan la razón mutuamente, cada uno asume la representación asociada al término que pertenece a su acervo y que, prácticamente, es en realidad el único mensaje que atraviesa el espejo existente entre los dos.

\section{c. Transacciones explicativas}

Para el discurso médico, los procesos infecciosos -entre los que se incluyen las enfermedades que estamos considerando- proceden del exterior y se interpretan y expresan frecuentemente mediante el uso de metáforas bélicas. En este sentido no es infrecuente escuchar de los facultativos que se trata de enfermedades que "atacan" al individuo poniendo en juego sus "defensas" que, espontáneamente o con ayuda de los medicamentos, acabarán "derrotando" a los microbios (Sontag, 1996: 47).

Para una buena parte de nuestros informantes, la enfermedad se genera en el interior del cuerpo, aunque sea activada por un estímulo externo, y debe ser expulsada al exterior. Con frecuencia se interpreta como la activación de un mal congénito, a veces relacionado con la naturaleza constitucional que ya hemos comentado. En este sentido se dice que el mal "foga”, tanto en un contexto físico como psíquico. Así, por ejemplo, las enfermedades "de los nervios" se valen de la ira para "fogar" en un proceso de limpieza o purificación. En una

produce la legitimación del rol de enfermo por parte del profesional. Cuando dicho rol no es certificado el paciente acepta a menudo el veredicto médico y regresa a sus ocupaciones habituales, o bien consulta a otro facultativo para confirmar su estado de salud. En ciertas ocasiones, no obstante, el paciente trata de conseguir un determinado diagnóstico mediante sucesivas consultas con otros especialistas. A este fenómeno lo denomina "compra del diagnóstico" (Suchman, 1965: 114-128). Entendemos que, recíprocamente, se produce una "venta del diagnóstico" cuando un médico, al percibir la demanda del enfermo, trata de satisfacerla accediendo a su expectativa por motivos, en general, más relacionados con la ganancia económica que con la doctrina hipocrática. 
afección respiratoria se "echan los sapos fuera", expresión que traduce la expulsión del mal por mediación del material expectorado ${ }^{12}$.

La falacia comunicativa asienta en este caso sobre la metáfora del bien y del mal que se interpreta en términos militares desde la perspectiva profesional -defensas, lucha, ataque victoria, derrota- y en términos morales y espirituales desde la del paciente para quien, en definitiva, el devenir del proceso será siempre "lo que Dios quiera". Llama la atención la desigualdad entre ambos usos lingüísticos pues en un plano dialéctico, mientras la comunidad posee sus propias metáforas -vinculadas a sus procesos de producción material y cultural- el sector profesional las incorpora subliminalmente, sin llegar a tomar conciencia de una gran parte de las reglas que utiliza para decidir su modo de relacionarse con el paciente (Loayssa, 2005: 580-583). Posiblemente en esa asimetría en el intercambio lingüístico gravitan relaciones de poder, ya que la metáfora militar privilegia y exalta a las clases dirigentes, tanto en el contexto social como en el médico (Fernández, 1998: 144). Naturalmente el proceso aculturador, mediado por los medios de comunicación, ha ido añadiendo al acervo popular parte de esas nociones con diferente calado y casi siempre en un plano de reciprocidad. En este sentido no es infrecuente que pacientes le pregunten al médico que lee un resultado analítico "¿cómo tengo las defensas?”.

Como en el caso anterior, los actores se oyen y escuchan pero sólo se entienden parcialmente, aunque ambos creen estar compartiendo las mismas nociones generándose, una vez más, una conversión lingüística peculiar que da cohesión a la falacia, consistente en la transformación de conectores sin valor aparente en significantes asertivos. Así, el paciente esgrime un argumento explicativo de su dolencia y el médico, que no llega a comprender muy bien lo que significa pero que tampoco le concede valor para el proceso de entendimiento mutuo, verbaliza una expresión vacía de significado para terminar el discurso que había empezado. El paciente, ajeno a ese discurso interpreta esa expresión como un acuerdo y, mientras el médico sigue hablando y se siente escuchado, medita acerca de su próxima intervención ${ }^{13}$.

\section{d. Transacciones terapéuticas}

Constituyen, en la mayor parte de los casos, el grupo de mayor magnitud. En ocasiones, incluso, se soslayan los tres anteriores, cuando los usuarios acuden a la consulta médica para solicitar un fármaco que sea eficaz para aliviar su dolencia. En este grupo el objeto de transacción es el tratamiento médico y, esencialmente, el medicamento, pues los recursos populares y folks no son abordados por lo general en la relación médico-paciente. Para la mayor parte de nuestros informantes los medicamentos son realmente los que curan, son las "balas mágicas", como las definía Ehrlich. De hecho, muchas consultas médicas parecen en realidad, debido a las peculiaridades del sistema sanitario español, prácticas de autoasistencia en las que interviene un profesional, en las que el paciente acude a la consulta a recoger un "vale descuento" para el medicamento que desea adquirir en la farmacia.

En este sentido el pueblo médico pondera especialmente los medicamentos antibióticos

12 En realidad esta expresión se asocia a todo proceso de curación, cualquiera que sea su causa: una fractura ósea que va consolidando, una diarrea que va cediendo, la mejoría en un estado de postración causado por una intervención quirúrgica, etc. Los "sapos” no deben identificarse por tanto con microbios ni miasmas sino con la esencia misma del mal que aflige al individuo.

13 Parece conveniente reseñar en este lugar el valor simbólico del discurso médico. Muchos informantes se maravillan de cómo los médicos "pueden hablar tanto" y lo atribuyen a que "han estudiado" comparándolos tácitamente con los curas, ya que constituyen las dos titulaciones superiores que han estado presentes en el medio rural a lo largo de la historia. En ambos casos se interpreta que el discurso no tiene como función principal la transmisión de mensajes explícitos sino servir de contribución al prestigio profesional de su emisor. Muchos términos y expresiones médicas resultan indescifrables para los pacientes, de igual modo que acontecía hasta hace pocas décadas con el latín, lengua que utilizaban los sacerdotes para oficiar la misa. 
que, en el caso de los problemas respiratorios agudos, considera de primera elección ${ }^{14}$. También se priorizan unas formas de administración sobre otras, por ejemplo los fármacos inyectados son preferidos a los ingeridos. A los supositorios -hoy en día relegados a un uso muy escaso- se les atribuye un poder intermedio entre las inyecciones y las pastillas. Los jarabes son los medicamentos que gozan de menor predicamento entre nuestros informantes y constituyen, en cualquier caso, lo mínimo que un médico a su juicio debe recetar.

Otros elementos significativos para la elección del fármaco son la eficacia probada tras el uso por otros miembros de la red social, el precio, el color ${ }^{15}$, la densidad o el tamaño de la dosis. Por otra parte, muchas personas expresan "tener fe" en determinados medicamentos con los que están familiarizadas y privilegian su consumo sobre otras preparaciones específicas porque los consideran idóneos para la expresión personal de sus dolencias ${ }^{16}$.

En este grupo de transacciones los interlocutores se oyen y entienden pero, a menudo, no se creen. En realidad su comunicación discurre en un ámbito subliminal, en el que cada uno de ellos intuye por qué el otro dice lo que dice. Muchos pacientes entienden, por ejemplo, que los médicos reciben instrucciones de sus superiores para ahorrar y por eso tienden a recomendar los medicamentos más baratos, o bien que no recetan antibióticos porque no les reconocen la eficacia que, a su modo de ver, poseen. En consecuencia se ven obligados a contender con dichos facultativos para conseguir que les receten los fármacos a los que invisten de mayor prestigio. Los médicos, por su parte, interpretan por lo general que los pacientes sobrevaloran la acción de los antibióticos o que buscan un prestigio social basado en el consumo de un determinado preparado comercial. Sin embargo, tras un equívoco intercambio de puntos de vista, se genera finalmente una prescripción y ambas partes quedan en alguna medida satisfechas del resultado de la entrevista.

\section{Consideraciones finales}

Los modelos propuestos para explicar cuanto acontece en la entrevista médico-paciente han ido evolucionando históricamente desde las perspectivas funcionalistas, que la definían en base a relaciones de paternalismo, en las que el médico detenta todo el poder y toma la mayor parte de decisiones, hasta planteamientos intersubjetivos en los que se parte del hecho de que ambos actores poseen sus propias representaciones, que deben ser respetadas. Para Balint en esta catarsis y no en el avance tecnológico reside básicamente la capacidad de la medicina de progresar (Balint, 1961). Esto implica la necesidad de trascender el rol autoritario del etiquetaje como conducta biopolítica ejercida por los médicos para corregir la desviación social, como postula Goffman (2004).

A pesar de esta constatación una parte mayoritaria de análisis de la relación médicopaciente se realiza desde perspectivas médicocéntricas, con frecuencia buscando la optimización en los procesos de educación del usuario.

Un enfoque más amplio del encuentro clínico nos la proporciona la sociolingüística interaccional, que muestra cómo en esa relación se pueden producir diferentes estrategias

14 El propio discurso médico-científico ha empoderado este tipo de fármaco desde la síntesis de la penicilina y su comercialización en la quinta década del siglo XX. La industria farmacéutica contribuyó en gran medida a su concepción como una panacea, que permeó rápidamente entre la población incluso como medida preventiva, hecho que se refleja en nuestra etnografía en expresiones acerca de su uso como "para que no vaya la cosa a más", "porque antes se cura lo poco que lo mucho", etc.

15 Acerca de las preferencias de los pacientes por determinados colores de los fármacos, véase More, Aarti T.; Srivastava, R.K. (2009).

16 Esta noción nace de la convicción de que existe una especificidad en el modo individual de padecer una misma enfermedad o síntoma y se expresa en afirmaciones como: "a todo el mundo no le prueba igual el medicamento", "lo que es bueno pa unos no es bueno pa otros", "a mí lo único que me va bien para esto es...". A menudo más que de principios activos se trata de formatos comerciales y la fe en ellos mengua cuando el fabricante cambia el color de la cápsula o el cartonaje del jarabe. 
de comunicación o voces, tanto por parte del médico como del paciente. En relación al discurso médico, Cordella clasifica estas voces en voz médica, voz educadora y voz empática que, respectivamente, tienen la función de buscar información sobre la salud del paciente, explicarle su aflicción y la alternativa terapéutica desde el punto de vista médico y ayudarle a expresar sus pensamientos y sentimientos (Cordella, 2002: 117-144). En todas ellas puede darse el fenómeno del doble espejo pero quizá la más adecuada para explicar la reflexión de la información sea la voz empática, particularmente en cuanto se refiere a la función discursiva de ayudar al paciente en la narración de su propia historia. Así, el uso de marcadores de continuidad discursiva ${ }^{17}$ al mismo tiempo que favorecen la elaboración de la narrativa del paciente, cumplirían la función de los conectores asertivos a los que nos hemos referido al analizar las transacciones explicativas, validando empíricamente la construcción del paciente desde la perspectiva de éste. Con los mismos presupuestos teóricos se produciría, obviamente, un efecto recíproco cuando es dicho paciente quien los usa, dando a entender al profesional que sus nociones son compartidas.

Esta misma autora también observa en el paciente cuatro voces distintas a las que llama "del iniciador", "del narrador de historias", "de la competencia" y "del comunicador social" (Cordella, 2004: 149-183) pero en ninguna de ellas parece visibilizarse una "voz del exhorto" como la que hemos observado frecuentemente en las consultas médicas reivindicando distintos aspectos del orden social. Así, expresiones como: "dígale que no beba tanta cocacola... [a mi marido]" "que no coma tantas pipas... [a mi marido]" "dígale que no se duche tanto... [a mi hija]”, revelan normas sociales implícitas que castigan el desprestigio sexual -los hombres no beben coca-cola-, la pobreza -comer muchas pipas da a entender que se padece hambre o que la esposa no cumple su papel de intendente doméstica- o la prostitución -sólo las prostitutas necesitan ducharse todos los días, porque se acuestan con muchos hombres-, tres causas de desorden social que mantienen una continua vigilancia colectiva en la comunidad que hemos estudiado. Llama la atención en el trabajo de Cordella que la comunicación simpatética es la más valorada en la consulta médica frente a la competencia médico-técnica, relación especialmente desproporcionada en el colectivo femenino (Cordella, 2004: 182), que es el mayor frecuentador de las consultas clínicas y el garante institucional del "orden saludable" o "capital de salud" en la familia (De las Heras 2013: 689). Esta jerarquización sería coherente con la disrupción entre los mensajes aparentes y los que realmente son capaces de atravesar el doble espejo existente entre médicos y pacientes a lo largo del encuentro clínico.

\section{Bibliografía}

ALMEIDA FILHO, Naomar

2007 "Por una epidemiología con (más que) números: cómo superar la falsa oposición cuantitativo-cualitativo". Salud colectiva, 3 (3): 229-233.

ALMEIDA FILHO, Naomar; CASTIEL, Luis David \& AYRES, José Ricardo

2009 "Riesgo: concepto básico de la epidemiología". Salud Colectiva, 5 (3): 323-344.

BALINT, Michel

1961 El médico, el paciente y la enfermedad. Buenos Aires: Libros básicos.

BARRETO, Mauricio L; ALMEIDA-FILHO, Naomar \& BREILH, Jaime

2001 "Epidemiology is more than a discourse: critical thoughts from Latin America". J. Epidemiol. Community Health, 55: 158-59.

17 A lo largo del encuentro clínico el discurso de ambos actores aparece salpicado de expresiones vacías desde el punto de vista lingüístico, como "claro", "mmmmm", "ya", que poseen a menudo un claro valor simbólico de refrendo para el interlocutor al que van dirigidas. 
CORDELLA, Marisa

2002 "La interacción médico-paciente en escrutinio: un estudio de sociolingüística interaccional. Onomazein, 7: 117-144.

2004 The dynamic consultation: a discourse analytical study of doctor-patient communication. Amsterdam/Philadelphia: John Benjamins.

DE LAS HERAS SALORD, Jaime

2013 Vivir, enfermar y morir en Casas de Juan Núñez (1871-2005). Ciudad Real: CRM.

2014a "Flujos históricos de poder en Atención Primaria: el caso de Casas de Juan Núñez". En Campos, R.; González de Pablo, A.; Porras, M. I. y Montiel L. Medicina y poder político: 149-154. Madrid: SEHM/UCM.

2014b "Formas de curanderismo en la Manchuela albacetense. Identidades y paradigmas". Revista de Dialectología y Tradiciones Populares, 69 (1): 209-228.

2015 "Espiritualidad, salud y circularidad en Casas de Juan Núñez". Gazeta de Antropología, 31 (1): artículo 09.

FAINZANG, Sylvie

2002 "Lying, secrecy and power within the doctorpatient relationship". Anthropology \& Medicine, 9 (2): 117-133.

FERNÁNDEZ, James Williams

1998 "El difícil diálogo de la Antropología con la Biomedicina", en J. Fernández García y A. Castillo Ojugas (Eds.) (1998) La medicina popular española: trabajos dedicados al Dr. Antonio Castillo de Lucas en el centenario de su nacimiento, pp. 141-150. Oviedo: XIII Congreso Nacional de la Asociación de Médicos y Escritores Artistas

FOUCAULT, Michel

1996 La vida de los hombres infames. La Plata (Argentina): Editorial Altamira.

FRESQUET FEBRER, Josep Lluís \& AGUIRRE MARCO, Carla Pilar

2006 Salut, malaltia i cultura. València: Universitat de València.

GERVÁS Juan \& HERNÁNDEZ AGUADO Ildefonso

2011 "Ética y salud pública. El caso de la gripe A (H1N1), 2009-2010”. Gestión Clín Sanit., 13: 123-27

GOFFMAN, Erwing

2004 Internados. Madrid: Amorrortu.

GÓMEZ ESTEBAN, Rosa

2002 El médico como persona en la relación médico-paciente. Madrid: Ed. Fundamentos.

GONZÁLEZ CHÉVEZ, Lilian \& HERSCH-MARTÍNEZ, Paul

1993 "Aportes para la construcción del perfil epidemiológico sociocultural de una comunidad rural”. Salud pública de México, 35 (4): 393-402.

HSU, J. C.; CHAN, P. S.; TANG, F.; MADDOX, T. M. \& MARCUS, G.

2015 "Oral Anticoagulant Prescription in Patients With Atrial Fibrillation and a Low Risk of Thromboembolism". JAMA Intern Med., 175 (6): 1062-1065

LOAYSSA LARA, José Ramón

2005 Teoría declarada y teoría en la acción de los médicos sobre la relación médico-paciente. Tesis doctoral dirigida por Fermín González García, Universidad Pública de Navarra.

MARTÍNEZ HERNÁEZ, Ángel

2008 Antropología médica. Barcelona: Anthropos.

MENÉNDEZ SPINA, Eduardo Luis

1992 "Modelo hegemónico, modelo alternativo subordinado, modelo de autoatención. Caracteres estructurales". En Campos, R. (comp.) La Antropología médica en México, tomo I: 97-114, México DF: Instituto Mora-Universidad Autónoma de México.

2003 "Modelos de atención de los padecimientos: de exclusiones teóricas y articulaciones prácticas". Ciència \& Saúde Coletiva, 8 (1): 185-207.

2008 "Epidemiología sociocultural: propuestas y posibilidades". Región y sociedad, $\mathrm{n}^{\circ}$ especial: 5-50.

2009 De sujetos, saberes y estructuras: Introducción al enfoque relacional en el estudio de la salud colectiva. Buenos Aires: Lugar Editorial. 
MINAYO, Maria Cecilia \& SANCHES, Odécio

1993 "Quantitativo-Qualitativo: Oposição ou Complementaridade?" Cad. Saúde Públ., 9 (3): 239-262.

MONKS, Judith A.

2000 "Talk as social suffering: Narratives of talk in medical settings". Anthropology \& Medicine, 7 (1): 15-38.

MOORE, Philippa; RIVERA, Solange \& CORBALÁN, Javiera

2006 "Cómo transmitir la evidencia a los pacientes: El médico como comunicador de riesgo". Rev Méd Chile, 134: 385-390.

PARSONS, Talcott

$1984 \quad$ El sistema social. Madrid: Alianza editorial.

RODRÍGUEZ ZOYA, Paula Gabriela

2010 "La medicalización como estrategia biopolítica". A Parte Rei. Revista electrónica de filosofía, 70. Disponible en: http://serbal.pntic.mec.es/ cmunoz11/zoya70.pdf (Consultado el 22/10/2015).

SCHEPER-HUGES, Nancy

1997 La muerte sin llanto. Violencia y vida cotidiana en Brasil. Barcelona: Ariel.

SEARLE, John R.

1980 "Minds, brains, and programs". Behavioral and Brain Sciences, 3 (3): 417-457.

SONTAG, Susan

1996 La enfermedad y sus metáforas. Madrid: Taurus.

SRIVASTAVA, R.K.; MORE, AARTI T.

2010 "Aesthetic considerations for pharmaceutical OTC (over the counter) products". Int. J. of Biotechnology, 11 (3/4): 267-283.

SUCHMAN, Edward A.

1965 "Stages of illness and medical care". J Health Human Behav, 6: 114-128.

TOMLJENOVIC, L.; SPINOSA, J. P.; SHAW, C. A.

2013 "Human papillomavirus (HPV) vaccines as an option for preventing cervical malignancies: (how) effective and safe?" Curr Pharm Des, 19 (8): 1466-87.

TURING, Alan Mathison

1950 "Computing Machinery and Intelligence". Mind, 59: 433-460. 